\title{
How travel purpose interacts with predictors of individual driving behavior in
} greater Montreal

3

4

5

6

\author{
James DeWeese \\ School of Urban Planning \\ Suite 400, 815 Sherbrooke St. W. \\ Montréal, Québec, H3A 0C2 Canada \\ McGill University, Montreal, QC, Canada \\ Email: james.deweese@mail.mcgill.ca
}

\author{
Ahmed El-Geneidy \\ School of Urban Planning \\ McGill University \\ Suite 400, 815 Sherbrooke St. W. \\ Montréal, Québec, H3A 0C2 Canada \\ Tel.: 514-398-4058 \\ Fax: 514-398-8376 \\ E-mail: ahmed.elgeneidy@mcgill.ca
}

Word Count: 6,284 words +4 tables $=7,284$ words

For Citation Please use: DeWeese, J., \& El-Geneidy, A. (2020). How travel purpose interacts with predictors of individual driving behavior in greater Montreal. Transportation Research Record, (2674),938-951.

July 2019 


\begin{abstract}
Rising transport emissions represent a significant challenge for policymakers. Two principal options exist to reduce emissions: Make driving less polluting or reduce driving overall. Though cities have a role to play in both approaches, the levers that may influence the latter more squarely align with municipal competences regarding the urban form. This paper aims to refine our understanding of the relationship between urban form and driving behavior by exploring whether accessibility - the ease of reaching desired destinations-exerts a different influence on driving mode choice and total distance depending on travel purpose. We rely on disaggregate data from the 2013 Montreal (Quebec) Origin-Destination survey and employ a two-step "hurdle" approach with multilevel logistic and linear models. We find that both local and regional accessibility possess statistically significant and negative impacts on driving mode choice and vehicle distance driven by Montreal drivers. Regarding the decision to drive, regional accessibility, as defined by transit-accessible jobs, appears to exert a greater impact than local accessibility, as measured by Walk Score across all purposes. When considering total kilometers driven, however, the relative impact of both types of accessibility varies. Overall, and for work and school driving, regional accessibility is correlated with the greatest declines in distance driven. For healthcare and discretionary travel, local accessibility is correlated with a larger decline in total driving distance. Our findings also highlight the profound impact of other explanatory factors, particularly car ownership, suggesting additional policy approaches for municipal decision makers to reduce vehicle kilometers traveled (VKT).
\end{abstract}

Keywords: Vehicle Miles Traveled, Vehicle Kilometers Traveled, Driving Behavior, Mode Choice, Accessibility 


\section{INTRODUCTION}

Human-induced climate change represents one of the most significant threats to cities and their residents over the short-, medium- and long-term. (1). In the United States, transport-related emissions greenhouse gas emissions (GHGs) constituted 29\% of total GHGs in 2017 (2). In Canada, transport GHGs have steadily increased since 1990 (3). Indeed, transport was responsible for nearly 25 percent of Canada's global warming emissions in 2017, ranking as the second-largest source by economic sector (3). Although heavy vehicles and light-duty trucks accounted for much of the increase, personal automobile travel continues to produce a significant portion of the transportation-related total (3). Reducing emissions from personal vehicle travel therefore represents a key challenge for combating climate change at the local and national levels.

Cities throughout Canada and across the world have begun considering options to reduce transport-related emissions. There are two principal approaches to reducing road-travel emissions. One is to reduce emissions per kilometer traveled by switching to electrical vehicles or other lowercarbon fuel sources; the other is to reduce total kilometers traveled (VKT), which yields numerous additional environmental and health-related benefits $(4 ; 5)$. Cities and other local policymakers possess a range of tools within their traditional municipal competencies regarding land-use and transport systems to reduce the number of people who choose to drive at all (mode shifting) and the distance they travel when they do (6-8).

Through regulations such as zoning, taxing and spending, cities can directly and indirectly shape many of the elements of the urban form, dubbed the 5Ds: density, diversity, design, distance to transit and destination accessibility (9). Accessibility sits at the intersection of these factors and remains an area of sustained interest for researchers. $(10 ; 11)$. In its simplest form, accessibility measures the ease of reaching opportunities (12). But the unassuming definition belies the conceptual power it boasts as a composite measure that unifies two important, but frequently siloed, considerations in transport planning: mobility and proximity (13). It also represents the cumulative interaction of four discrete factors: land-use, transport, individual characteristics and time (14). In effect, the modern concept of accessibility directly connects land-use patterns and transport-system characteristics. For city decisionmakers, then, accessibility is an especially valuable metric because it offers a wholistic and simultaneous assessment of these characteristics.

Using disaggregate travel data from Montreal, Quebec's 2013 origin-destination survey, this paper explores accessibility's impact on driving behavior at two spatial scales: (1) local accessibility - the availability of walking-distance amenities as represented by neighborhood-level Walk Score assessments and (2) regional transit accessibility, defined here as the number of jobs that can be reached by public transit in a given time from the respondent's home census tract. Travel choices and behavior are highly idiosyncratic and influenced by a constellation of factors, including personal characteristics and the purposes for which trips are made (15). To address some of this variety and to support more nuanced policy recommendations, this research takes the additional step of considering how local and regional accessibility influence travel for different purposes: (1) overall travel, (2) work, (3) education, (4) healthcare, and (5) "discretionary" travel, consisting of leisure, socialization, shopping or errands. Conceptually the travel purposes considered represent varying degrees of individual discretion regarding time and mode and are thus expected to respond differently to planning interventions aimed at promoting different types of accessibility. 


\section{LITERATURE REVIEW}

The impact of the built form on travel behavior is among the most researched and, at times, contentious topics among planners and transport researchers. Overall, it is safe to state that the preponderance of published articles suggests that varying combinations of the 5Ds display statistically significant relationships with reductions in different measures of vehicle distance traveled $(8 ; 16 ; 17)$. Yet, despite sustained scholarly interest, the exact nature of the relationship between the urban form and travel preferences and behavior, its causal direction, and the intensity of its impact, remains opaque and, in some cases, disputed $(5 ; 8 ; 18 ; 19)$.

As a subcomponent of the 5Ds, destination accessibility represents a major line of inquiry in part because it serves as a valuable composite indicator, linking elements of the land use and transport systems (20). For planners and city policymakers, it is a particularly useful concept because, depending on its application, it can help achieve broader environmental and socioeconomic outcomes (21). Location-based accessibility measures, which calculate opportunity tallies for specific zones, are by far the most commonly applied. Within these, two more frequently applied measures exist: cumulative opportunities and gravity $(10 ; 22)$. Cumulative opportunities measures are those that tally the number of opportunities that can be reached from a given origin without exceeding a specified travel-cost threshold, commonly time, distance or cost.

Of the researchers whose studies have examined the impact of accessibility, most have identified a statistically significant, though sometimes moderate, relationship $(5 ; 23 ; 24)$. In the study that most directly influenced our approach for this analysis, Ewing et al. (24) find that both car and transit accessibility measured by jobs reachable within different times are associated with decreases in household VMT. In an earlier study, Cervero \& Duncan (2006) find that the relative impact of accessibility on vehicle distance traveled, as measured by elasticities, can even outweigh that of individual and household characteristics (23). Indeed, they find that accessibility-as measured by jobs and housing balance - reduces total travel distance more than retail balance. (25). Two key issues arise when looking across these studies and these issues have implications for the direction of this and future research. First, considerable variance in household or individual vehicle distance traveled often remains unexplained in even the most robust models $(5 ; 19 ; 24)$. Second, there is considerable variation in vehicle distance traveled outcomes across urban and individual contexts making further research into different environments and under different conditions particularly $(8 ; 26)$.

\section{DATA AND STATISTICAL ANALYSIS}

Mode and travel distance data were obtained from the 2013 edition of Montreal's origindestination survey, the most recent publicly available version (27). Conducted every five years since 1970, this survey collects information from a random sample of tens of thousands of Montreal-area households regarding travel habits over the preceding 24-hour weekday period. Our analysis draws on a subset of this data representing people who made trips fully within the local and regional public transit-service areas. To streamline calculations, we further restricted our analysis to people whose trips consisted of origin-destination pairs located within 100 kilometers of the Montreal Island center as measured by road-network travel distance. Any records with missing data regarding actual destinations, mode or household characteristics were discarded. Finally, we sought to identify the influence of individual, household and neighborhood characteristics on driving behavior. We therefore focused exclusively on those people who could be reasonably classified as "potential drivers." For purposes of this analysis, a potential driver means a licensed driver from a household with at least one car (28). 
For each of the trip segments recorded in the survey, we classified the mode as primary driver or other. Because our primary research question focuses on built-environment determinants of (1) the decision to drive and (2) the distance driven once that decision is made, a distinction between alternative modes was not considered important. To calculate driving distance, we relied on the ArcGIS Network Analyst toolbox applied to a road network downloaded using OSMnx (29). (This road network was downloaded in April 2019 and may therefore reflect changes not present when the 2013 O-D survey was completed.)

Before assigning trip purposes to travel types, we grouped individual trip segments into home-based loops, a common definition for a trip chain. We then assigned a primary purpose to each loop from one of four categories (28). Trip-purpose categories included work, school, healthcare and "discretionary," which encompasses leisure, recreation, social calls and shopping. Based on the assumption that work, school and, to a certain extent, healthcare have schedules and locations that are not defined wholly by the traveler, they were considered to be primary purposes for any loop for which they were present. All loops lacking segments for these "mandatory" activities were classified as "discretionary." Creating loops beforehand ensured that all reported vehicle travel, including returns home, could be classified according to the trip purposes of interest.

For our measures of local accessibility, we relied on Walk Scores for home neighborhoods (30). For regional accessibility, we employed a transit-based cumulative-opportunities measurement with a 45-minute threshold. For the transit network, we assembled GTFS data for all transit agencies providing service in the study area. To more closely align with conditions at the time of the O-D survey, we used archived General Transit Feed Specification (GTFS) data from November 2013, the oldest data for which data were consistently available from all the agencies. We then calculated travel times between all Census Tract centroids using the ArcGIS Network Analyst Extension for Transportation Analysis developed by Melinda Morang. We derived Census tract jobs figures from Census Work Flows (31). When calculating jobs accessibility, we established the 45-minute threshold because it most closely aligns with the average transit commuting time in Montreal (32). To enable direct comparison of the impacts of local and regional accessibility, we normalized both using z-scores.

\section{Modeling}

Modeling individual VKT from our data set presented two interrelated challenges: The data are generally not normally distributed, requiring a log transformation, but also contain many zero values, which cannot be directly log transformed. We employed a two-step "hurdle process" as described by Ewing et al. 2015. (24). We first constructed a logistic regression to explain the binary choice to drive or not. As the second step, we constructed a multi-level linear regression model to explore the determinants of driving distance among the subset of respondents who did report driving activity for each purpose. This two-step approach is generally consistent with the policy objectives considered here: First keep people out of cars and, when that is unlikely or impossible, figure out how to get them to drive less.

For both the logistic and linear models we used a nested, multi-level mixed effects approach using the $\mathrm{R}$ statistical programming language. We placed individuals within households and households within census tracts. This approach aims to address the fact that people within the same households, and households within the same neighborhood, are likely to share certain characteristics that are not otherwise accounted for within the model $(24 ; 33)$.

We included the following independent variables for individual characteristics: age, gender, employment and/or student status and possession of a driver's license. For purposes of 
modeling, we organized employment status into three bins reflecting the assumed differences in the associated need to travel routinely outside the home (full-time; part-time and/or student; homemaker, retired and not employed). For household characteristics, we included household income, the number of preschoolers, the number of school age children, the number of adults and the number of vehicles in a household.

For our neighborhood and regional characteristics, we included two measures of accessibility, which reflect different geographic scales and types of destinations. For local accessibility, we relied on a 2010 database of neighborhood-level walkability scores from Walk Score, a private company that prepares a publicly available gravity-based assessment of amenities within 1 mile of locations. For regional accessibility, we used transit-based jobs accessibility defined as the number of jobs reachable within 45 minutes from the centroid of each home census tract. Initially, we sought to include vehicle-based jobs accessibility and a transit-to-car accessibility ratio, but the variables were found to be too closely correlated with transit accessibility.

When evaluating mode and distance by segregated trip purpose, we also included travel for other purposes as independent variables to account for possible time competition and fatigue from other travel. For example, when analyzing work-related driving travel and VKT as dependent variables, we included VKT for school, healthcare and discretionary travel as explanatory variables. Our modeling does not directly consider the effects of self-selection, a key component of the causal relationship between built-form and other related determinants of VKT. The use of multi-level modeling and the inclusion of socio-economic control variables, however, can help account for some of this phenomenon's impact. Also, we assume consistent accessibility throughout the day, which has been demonstrated to serve as a reliable measure (34; 35). Many trips, however, took place at different times, introducing unexplained variance into the model.

\section{RESULTS}

\section{Descriptive Statistics}

The total number of potential drivers who traveled outside the home during the survey period numbered 63,538 . Of these potential drivers, more than $75 \%$ reported driving at least once during the survey period, see

Table 1. Among the 37,104 people who reported work travel outside the home, a similar percentage reported driving for this purpose. Of the 2,750 people who traveled for healthcare, $65 \%$ drove. At the other end of the spectrum, only $38 \%$ of 4,999 school travelers and $36 \%$ of 63,149 "discretionary" travelers drove.

\section{Table 1 Summary of potential and actual drivers segmented by trip purpose}

\begin{tabular}{lccc}
\hline \hline Travel Type & $\begin{array}{c}\text { All } \\
\text { Travelers }\end{array}$ & Drivers & $\begin{array}{c}\text { Percent } \\
\text { Drivers }\end{array}$ \\
All types (combined) & 63,538 & 48,551 & 76 \\
Work & 37,104 & 28,298 & 76 \\
School/Education & 4,999 & 1,908 & 38 \\
Healthcare & 2,750 & 1,808 & 66 \\
Discretionary (recreation, shopping, socialization, pick-ups) & 63,149 & 23,206 & 37
\end{tabular}


Within the sample subset, households on average contained 2.9 people -2.3 adults and 0.7 children. On average $46.7 \%$ of adults in each household reported being a full-time employee. Households averaged a car-to-driver's license ratio of nearly 1 to 1 .

Table 2 Summary Statistics for Travel, Individual, Household, Neighborhood and Regional Variables (Based on subset of people having a driver's license coming from a household with at least one car).

\begin{tabular}{|c|c|c|c|c|c|}
\hline Statistic & Mean & St. Dev. & Min & Max & Source \\
\hline \multicolumn{6}{|c|}{ Individual travel $(\mathrm{km})$} \\
\hline All VKT & 20.2 & 20.5 & 0.0 & 81.2 & Calculated \\
\hline Work VKT & 13.0 & 19.2 & 0.0 & 81.2 & Calculated \\
\hline School VKT & 0.9 & 5.9 & 0.0 & 81.0 & Calculated \\
\hline Healthcare VKT & 0.6 & 4.7 & 0.0 & 160.1 & Calculated \\
\hline Discretionary VKT & 5.8 & 12.6 & 0.0 & 81.2 & Calculated \\
\hline \multicolumn{6}{|c|}{ Individual characteristics } \\
\hline Age & 47.4 & 15.8 & 16.0 & 98.0 & 2013 O-D Survey \\
\hline Age (squared) & $2,498.0$ & $1,534.8$ & 256.0 & $9,604.0$ & 2013 O-D Survey \\
\hline Female (1) & 0.5 & 0.5 & 0.0 & 1.0 & 2013 O-D Survey \\
\hline Student & 0.1 & 0.3 & 0.0 & 1.0 & 2013 O-D Survey \\
\hline Full-time & 0.6 & 0.5 & 0.0 & 1.0 & 2013 O-D Survey \\
\hline Part-time & 0.1 & 0.2 & 0.0 & 1.0 & 2013 O-D Survey \\
\hline Homemaker & 0.0 & 0.1 & 0.0 & 1.0 & 2013 O-D Survey \\
\hline Retired & 0.2 & 0.4 & 0.0 & 1.0 & 2013 O-D Survey \\
\hline Not employed & 0.1 & 0.3 & 0.0 & 1.0 & 2013 O-D Survey \\
\hline \multicolumn{6}{|c|}{ Household characteristics } \\
\hline Cars per household & 1.8 & 0.9 & 1.0 & 14.0 & 2013 O-D Survey \\
\hline Adults per household & 2.3 & 0.9 & 0.0 & 13.0 & 2013 O-D Survey \\
\hline $\begin{array}{l}\text { School-age children per } \\
\text { household }\end{array}$ & 0.5 & 0.8 & 0.0 & 6.0 & 2013 O-D Survey \\
\hline Preschoolers per household & 0.2 & 0.5 & 0.0 & 5.0 & 2013 O-D Survey \\
\hline \multicolumn{6}{|c|}{ Neighborhood and regional characteristics } \\
\hline $\begin{array}{l}\text { Neighborhood Walk Score } \\
\text { (Local accessibility) }\end{array}$ & 56.0 & 23.0 & 0.0 & 100.0 & Walk Score \\
\hline Local accessibility (z-score) & 0.0 & 1.0 & -2.4 & 1.9 & Walk Score \\
\hline $\begin{array}{c}\text { Transit-accessible jobs by } \\
\text { census tract (Regional } \\
\text { accessibility) }\end{array}$ & $228,001.0$ & $273,827.0$ & 0.0 & $1,584,390.0$ & $\begin{array}{l}\text { STM, RTL, EXO, STL } \\
\text { GTFS, Statistics Canada }\end{array}$ \\
\hline Regional accessibility (z-score) & 0.0 & 1.0 & -0.8 & 5.0 & $\begin{array}{l}\text { STM, RTL, EXO, STL } \\
\text { GTFS, Statistics Canada }\end{array}$ \\
\hline $\begin{array}{l}\text { Percent of car jobs accessible } \\
\text { by transit in } 45 \text { minutes }\end{array}$ & 27.3 & 28.5 & 0.0 & 117.6 & $\begin{array}{c}\text { STM, RTL, EXO, STL } \\
\text { GTFS, Statistics Canada }\end{array}$ \\
\hline
\end{tabular}




\section{Spatial Patterns in Average Individual VKT}

As seen in Figure 1 our driving-behavior data presents clear spatial patterns that largely conform to our expectations. As one moves further from Montreal's downtown, VKT increases. The greatest average individual driving distances for all purposes are concentrated in suburban and exurban areas forming a ring around the Island of Montreal. By contrast, the denser inner-city areas tend to generate lower VKTs. The distribution of average work-related VKT highlights four outlying areas that defy this general pattern, potentially underscoring the value of commuter transit infrastructure and polycentric development as possible means to reduce individual VKT.
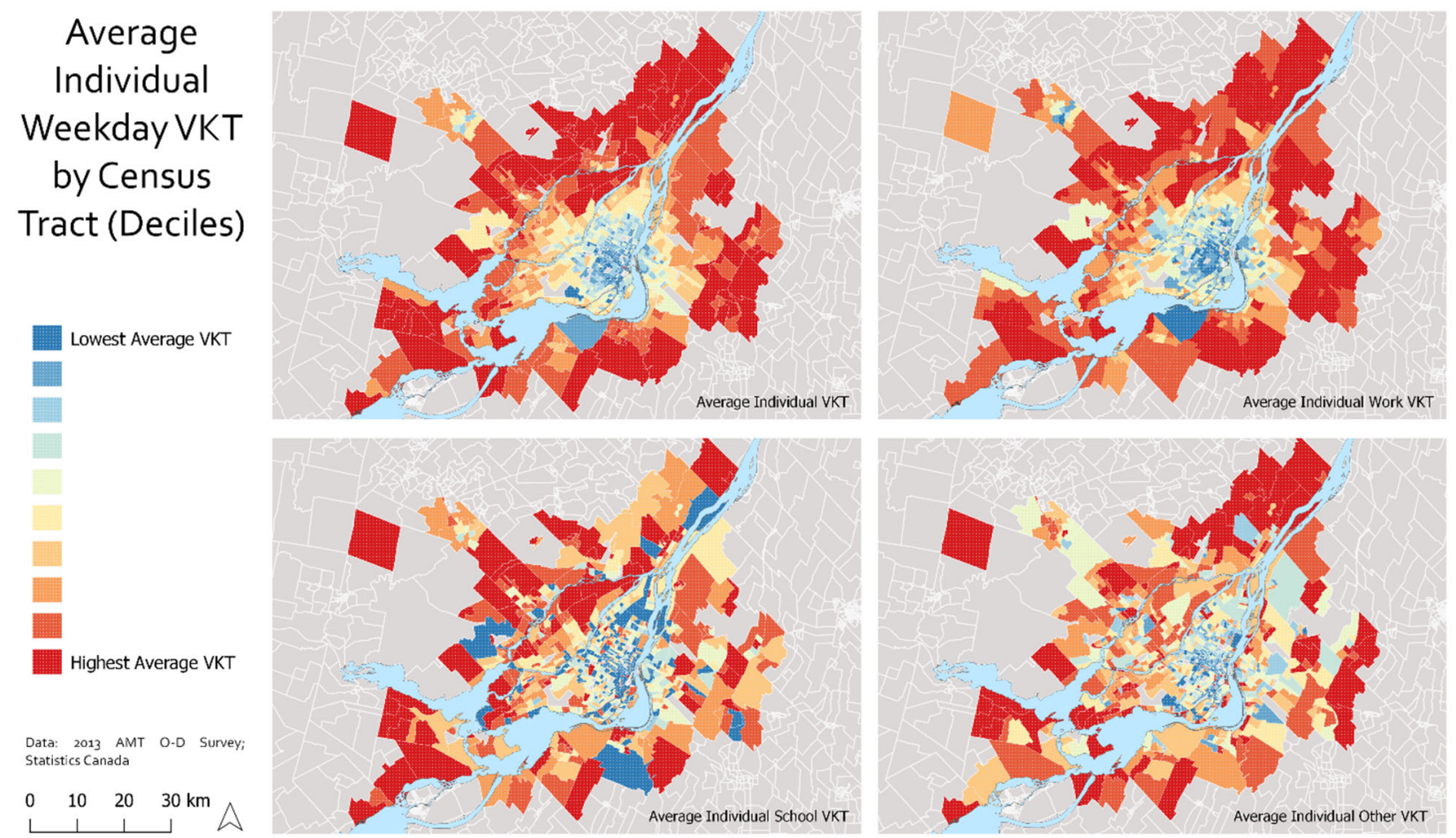

Figure 1 Average Individual Vehicle Kilometers Traveled by Census Tract

\section{To Drive or Not to Drive: That is the Regression}

As a first step in our analysis, we sought to determine when potential drivers - those who have a driver's license and come from a household with at least one car-become actual drivers. To that end, we explored two principal questions (1) which of the selected factors has an influence on the binary decision to drive or not to drive and (2) whether that influence is consistent across travel purposes. For this analysis, we relied on a multilevel mixed effects logistic regression for all people within our data subset who reported any travel for the categories we considered. The findings from the statistical models are reported in Table 3. 
Table 3 Results table for multilevel logistic regressions for odds of positive VKT for various travel purposes.

\begin{tabular}{|c|c|c|c|c|c|}
\hline Predictors & $\begin{array}{c}\text { Positive } \\
\text { VKT } \\
\text { Odds Ratios } \\
\end{array}$ & $\begin{array}{c}\text { Positive } \\
\text { Work VKT } \\
\text { Odds Ratios } \\
\end{array}$ & $\begin{array}{c}\text { Positive } \\
\text { School VKT } \\
\text { Odds Ratios } \\
\end{array}$ & $\begin{array}{c}\text { Positive } \\
\text { Healthcare VKT } \\
\text { Odds Ratios }\end{array}$ & $\begin{array}{c}\text { Positive } \\
\text { Discretionary VKT } \\
\text { Odds Ratios }\end{array}$ \\
\hline Age (years) & $1.0625^{* * *}$ & 1.039 & 1.262 & $1.0431^{* *}$ & $1.0333^{* * *}$ \\
\hline Age (sq.) & $0.9995^{* * *}$ & 1 & 0.998 & $0.9996^{* *}$ & $0.9998^{* * *}$ \\
\hline Female (y) & $0.5572^{* * *}$ & 0.623 & 0.795 & $0.6345^{* * *}$ & $0.6753^{* * *}$ \\
\hline $\begin{array}{l}\text { Part-time worker (vs. } \\
\text { full-time employed) }\end{array}$ & $0.3052^{* * *}$ & 0.391 & 1.176 & 0.677 & $0.4744^{* * *}$ \\
\hline $\begin{array}{l}\text { Unemployed or } \\
\text { homemaker (vs. full- } \\
\text { time employed) }\end{array}$ & 0.87 & 1.28 & 3.066 & 1.09 & $3.3160^{* * *}$ \\
\hline $\begin{array}{l}\text { Additional cars in } \\
\text { household }\end{array}$ & $2.5771^{* * *}$ & $3.3330^{* *}$ & $2.7792^{* * *}$ & $1.3810^{* * *}$ & $1.3298^{* * *}$ \\
\hline Adults in household & $0.6132^{* * *}$ & 0.574 & 0.649 & $0.7236^{* * *}$ & $0.7731^{* * *}$ \\
\hline $\begin{array}{l}\text { Preschoolers in the } \\
\text { household }\end{array}$ & $1.2960^{* * *}$ & 1.112 & 1.157 & 1.071 & $1.2974^{* * *}$ \\
\hline $\begin{array}{l}\text { School-age children } \\
\text { in the household }\end{array}$ & 1.071 & 1.033 & 0.792 & 1.071 & $1.2123^{* * *}$ \\
\hline $\begin{array}{l}\text { Lower-income } \\
\text { household }(<60 \mathrm{~K} \\
\text { CAD/yr) }\end{array}$ & $1.3760^{* *}$ & 1.771 & 1.634 & $1.2783^{*}$ & $1.1038^{* * *}$ \\
\hline $\begin{array}{l}\text { Medium-income } \\
\text { household ( } 60 \mathrm{~K} \text { CAD } \\
\text { to } 120 \mathrm{CAD} / \mathrm{yr})\end{array}$ & 1.064 & 1.155 & 1.136 & 1.075 & 0.994 \\
\hline $\begin{array}{l}\text { Transit-accessible } \\
\text { jobs within } 45 \\
\text { minutes }(10,000 \mathrm{~s})(\mathrm{z}- \\
\text { score })\end{array}$ & $0.7594^{* * *}$ & 0.721 & 0.7 & $0.7726^{* * *}$ & $0.8323^{* * *}$ \\
\hline $\begin{array}{l}\text { Home neighborhood } \\
\text { Walk Score (z-score) }\end{array}$ & $0.8739^{* *}$ & 0.844 & 0.809 & $0.8843^{*}$ & $0.9693^{* *}$ \\
\hline Positive Work VKT & & & $5.1819^{*}$ & $0.3037^{* * *}$ & $0.1767^{* * *}$ \\
\hline Positive School VKT & & 4.778 & & 1.252 & $0.4959^{* * *}$ \\
\hline $\begin{array}{l}\text { Positive Healthcare } \\
\text { VKT }\end{array}$ & & 1.91 & 7.769 & & $0.2049^{* * *}$ \\
\hline $\begin{array}{l}\text { Positive } \\
\text { Discretionary VKT }\end{array}$ & & 1.029 & 1.369 & $5.2825^{* * *}$ & \\
\hline (Intercept) & 0.558 & 0.536 & $0.0029^{* *}$ & 0.939 & $0.3358^{* * *}$ \\
\hline Observations & 63538 & 37104 & 4999 & 2750 & 63149 \\
\hline
\end{tabular}

For all travel purposes combined, car ownership in the household appear to exert the strongest positive influence on the likelihood of driving. For each additional car, the odds of driving increase 2.58 times, all else being equal. By contrast, the presence of additional adults in the household appears to possess a moderating influence, perhaps due to increased competition for cars. To a point, increasing age is significantly correlated with a higher likelihood of driving for all purposes combined, but among the disaggregated trip purposes, age is statistically significant 11 only for healthcare and discretionary driving. Both accessibility to jobs by public transport and 12 local accessibility (Walk Score) are statistically significant with a negative impact on the 13 likelihood of driving for all trip purposes combined and for discretionary travel, when holding all 
other variables constant. Interestingly neither shows an impact on the decision to drive to work. Overall, women are statistically far less likely to drive than men, all else being equal. This holds true for healthcare and discretionary travel, though not for work travel, where no statistically significant relationship emerges.

Relative to people from high-income households, people from lower-income households are more likely to travel by car for all purposes combined and for discretionary travel, with all other variables held constant. Because we control for overall accessibility from a traveler's home census tract, this somewhat surprising result may indicate that lower-income people travel to areas that are less well-served by alternative transport. That is to say, transit may currently be structured to provide access to job destinations that are more desirable or relevant to wealthier people than to people from lower-income households.

Having preschoolers, as opposed to school-age children, is correlated with a much higher likelihood of driving for all reasons combined, possibly owing to the perceived need to carry accoutrements such as strollers or supplies. Among all the explanatory variables, only the number of cars proved a statistically significant factor for the likelihood of driving for school or healthcare, all else being equal.

\section{Multi-Level Linear Regressions for VKT}

In the second step of this analysis, we modeled the relationship between the same set of explanatory variables and log transformed individual vehicle distance traveled by the subset of respondents who drove. Similar patterns of statistical significance emerge as with the logistic regression for positive VKT, though the direction of the relationship is not always the same. Table 4 shows the findings from the multilevel regression models.

\section{Total VKT}

Regarding driving for all purposes combined, all variables except being a part-time rather than full-time employee showed statistical significance, all else being equal. The number of cars per household has a positive and statistically significant impact on VKT. When holding other variables constant, each additional car in the household is associated with a nearly $5 \%$ increase in total individual VKT, perhaps as a result of reduced competition for vehicles within a household. Meanwhile, the number of adults represents a drag on individual VKT, potentially as a result of increased competition, while keeping all other variables constant.

Being from a lower-income household rather than a higher- income household is associated with driving $16 \%$ percent less total distance; being from a middle-income household is associated with driving 4\% less than a high-income household, while keeping all other variables equal at their means. These relationships could be explained by financial limitations imposed by lower incomes; a broader geographic dispersion of lower-income jobs, placing them in closer proximity to more people than higher-income jobs, which tend to be concentrated in central business districts; or a combination of both.

For all categories except healthcare, the model indicates that as people grow older, they drive more. This trend reverses at a certain point as illustrated by the statistical significance of the age-squared variable.

Both local and regional accessibility present a statistically significant negative impact on individual VKT for all purposes of travel combined, all else being equal. Local accessibility is associated with slightly greater declines in overall VKT than regional accessibility for all driving travel. Each point increase in the z-score of the home census tract Walk Score is associated with 
1 an approximately $10 \%$ decrease in VKT, all other variables held constant. Each increment in the

2 z-score for transit-accessible jobs corresponds to a decline of about $9 \%$, all else being equal.

Table 4 Results table for multilevel linear regressions for individual VKT for various

4 travel purposes.

\begin{tabular}{|c|c|c|c|c|c|}
\hline Predictors & $\begin{array}{c}\log (\text { total vkt) } \\
\text { Estimates }\end{array}$ & $\begin{array}{c}\log (\text { work vkt) } \\
\text { Estimates }\end{array}$ & $\begin{array}{c}\log (\mathbf{s c h o o l}) \\
\text { Estimates }\end{array}$ & $\begin{array}{c}\log (\mathbf{h e a l t h} \mathbf{v k t}) \\
\text { Estimates }\end{array}$ & $\begin{array}{c}\log (\text { discretionary } \\
\text { vkt) } \\
\text { Estimates }\end{array}$ \\
\hline Age (years) & $0.0170^{* * *}$ & $0.0294^{* * *}$ & $0.0361^{* * *}$ & 0.0077 & $0.0157^{* * *}$ \\
\hline Age (sq.) & $-0.0002^{* * *}$ & $-0.0003^{* * *}$ & $-0.0005^{* * *}$ & -0.0001 & $-0.0002^{* * *}$ \\
\hline Female (y) & $-0.1628^{* * *}$ & $-0.1967^{* * *}$ & $0.0580^{*}$ & -0.0368 & $-0.0969^{* * *}$ \\
\hline $\begin{array}{l}\text { Part-time worker (vs. } \\
\text { full-time employed) }\end{array}$ & -0.0362 & $-0.4222^{* * *}$ & $0.1502^{* *}$ & -0.2724 & 0.0615 \\
\hline $\begin{array}{l}\text { Unemployed or } \\
\text { homemaker (vs. full- } \\
\text { time employed) }\end{array}$ & $-0.4472^{* * *}$ & $-0.1117^{* *}$ & -0.0553 & -0.0244 & 0.0116 \\
\hline $\begin{array}{l}\text { Additional cars in } \\
\text { household }\end{array}$ & $0.0472^{* * *}$ & $0.0131^{*}$ & $0.0475^{* *}$ & -0.0359 & $0.0418^{* * *}$ \\
\hline Adults in household & $-0.0545^{* * *}$ & $-0.0442^{* * *}$ & -0.0019 & -0.0075 & $-0.0472^{* * *}$ \\
\hline $\begin{array}{l}\text { Preschoolers in the } \\
\text { household }\end{array}$ & $-0.0251^{* * *}$ & $0.0405^{* * *}$ & -0.0674 & 0.0048 & $-0.0734^{* * *}$ \\
\hline $\begin{array}{l}\text { School-age children in } \\
\text { the household }\end{array}$ & $-0.0123^{* *}$ & -0.0058 & $-0.0417^{* *}$ & $-0.0556^{*}$ & $-0.0432^{* * *}$ \\
\hline $\begin{array}{l}\text { Lower-income } \\
\text { household }(<60 \mathrm{~K} \\
\text { CAD/yr) }\end{array}$ & $-0.1777^{* * *}$ & $-0.1990^{* * *}$ & -0.0726 & -0.0983 & $-0.1482^{* * *}$ \\
\hline $\begin{array}{l}\text { Medium-income } \\
\text { household ( } 60 \mathrm{~K} \mathrm{CAD} \\
\text { to } 120 \mathrm{CAD} / \mathrm{yr})\end{array}$ & $-0.0449^{* * *}$ & $-0.0634^{* * *}$ & -0.0593 & 0.0047 & $-0.0428^{* *}$ \\
\hline $\begin{array}{l}\text { Transit-accessible jobs } \\
\text { within } 45 \text { minutes } \\
(10,000 \mathrm{~s})(\mathrm{z} \text {-score })\end{array}$ & $-0.0913^{* * *}$ & $-0.1198^{* * *}$ & $-0.2264^{* * *}$ & $-0.1418^{* * *}$ & -0.0173 \\
\hline $\begin{array}{l}\text { Home neighborhood } \\
\text { Walk Score (z-score) }\end{array}$ & $-0.1020^{* * *}$ & $-0.0749^{* * *}$ & $-0.0560^{* *}$ & $-0.1659^{* * *}$ & $-0.1432^{* * *}$ \\
\hline Positive Work VKT & & & $0.0114^{* * *}$ & $-0.0058^{* *}$ & $-0.0128^{* * *}$ \\
\hline Positive School VKT & & $0.0110^{* * *}$ & & -0.0013 & $-0.0121^{* * *}$ \\
\hline $\begin{array}{l}\text { Positive Healthcare } \\
\text { VKT }\end{array}$ & & 0.0003 & $-0.0147^{*}$ & & $-0.0085^{* * *}$ \\
\hline $\begin{array}{l}\text { Positive Discretionary } \\
\text { VKT }\end{array}$ & & $-0.0093^{* * *}$ & $-0.0100^{* * *}$ & $-0.0065^{* * *}$ & \\
\hline (Intercept) & $2.8929^{* * *}$ & $2.7078^{* * *}$ & $2.2681^{* * *}$ & $2.8187^{* * *}$ & $2.3708^{* * *}$ \\
\hline \multicolumn{6}{|l|}{ Random Effects } \\
\hline$\sigma^{2}$ & 0.76 & 0.54 & 0.39 & 0.21 & 0.81 \\
\hline$\tau_{00}$ & 0.06 house_id:ct & 0.06 house_id:ct & 0.06 house_id:ct & 0.66 house_id:ct & 0.12 house_id:ct \\
\hline $\mathrm{ICC}$ & $\begin{array}{l}0.02 \text { ct } \\
0.09\end{array}$ & $\begin{array}{l}0.03 \text { ct } \\
0.15\end{array}$ & $\begin{array}{l}0.04 \text { ct } \\
022\end{array}$ & $\begin{array}{l}0.02 \text { ct } \\
076\end{array}$ & 0.01 ct \\
\hline $\mathrm{N}$ & 34128 house_id & 21523 house_id & 1795 house id & 1749 house id & $\begin{array}{l}0.14 \\
18955 \text { house id }\end{array}$ \\
\hline & 805 ct & 732 ct & 413 ct & 466 ct & 722 ct \\
\hline Observations & 48551 & 28298 & 1908 & 1808 & 21536 \\
\hline $\begin{array}{l}\text { Marginal } \mathrm{R}^{2} / \\
\text { Conditional } \mathrm{R}^{2}\end{array}$ & $0.124 / 0.206$ & $0.083 / 0.221$ & $0.190 / 0.364$ & $0.084 / 0.785$ & $0.054 / 0.184$ \\
\hline
\end{tabular}




\section{Work-Related VKT}

Work-related VKT displays a similar pattern of statistical significance to overall VKT with a notable exception: The number of school-age children in a household does not have a statistically significant relationship, while part-time versus full-time employment does. Each additional household car increases driving distance by $2 \%$, while each additional adult in the household reduces personal VKT to work by 4\%, while keeping all other variables constant at their mean.

Being a woman is associated with driving $18 \%$ less, as is being from a lower-, rather than, higher-income household, all else equal. The age of children in the household influences workrelated travel. Work travel distance increases $4 \%$ for each preschooler in the household but declines $1 \%$ for each school-age child in the household, all else equal.

Local and regional accessibility have a significant influence on work-related travel. As expected, regional transit accessibility as measured by reachable jobs corresponds to greater reductions in work-related VKT. For each increase in the z-score for regional accessibility, workrelated driving distance is expected to drop about $11 \%$, all else being equal. Meanwhile, each increase in the z-score for Walk Score for a home neighborhood is associated with an approximately $7.5 \%$ decline in work VKT.

The impact of travel for other purposes appears to be mixed. Each additional kilometer traveled for school corresponds with a $1 \%$ increase in work-travel distance while each additional kilometer of discretionary travel corresponds with a $1 \%$ decrease in work travel distance, while keeping all other variables constant at their means.

\section{School Travel}

An increase in the number of cars in the household by one drives up distance traveled by $6 \%$, while each additional adult in the household correlates to a $1 \%$ decline in distance, keeping all other variables constant at their means. For each additional year in age, the expected VKT increases by $3 \%$, but then begins to decline, all else equal. Rather surprisingly, household income was not statistically significant for school-related VKT.

Again, both local and regional accessibility demonstrate a negative correlation with VKT. Regional accessibility displays a strong influence than local accessibility. For each additional increase in the z-score for transit-accessible jobs, school driving distance falls by about $22 \%$, all else being equal; each increase in Walk Score z-score relates to a 5.6\% decline in school driving distance.

Being a part-time worker or student corresponds with an increase of driving distance of nearly $16 \%$. The presence of school age children has a statistically significant negative relationship with individual VKT, with a decline of $4 \%$ distance for each additional school age child in the household, all else equal. For each added kilometer of discretionary driving, there is a $1 \%$ decline in school driving distance; meanwhile each additional kilometer of weekday work driving is associated with a $1 \%$ increase in school-related driving.

\section{Healthcare}

Few variables in the model show statistical significance with respect to healthcare distance driven, suggesting other factors more strongly influence driving distance for healthcare purposes. Indeed, only local and regional accessibility and work and discretionary driving appear to be significant at the 95\% confidence level. Each point increase in the z-score for the home neighborhood Walk Score corresponds to a decrease of $17 \%$ in healthcare VKT, all other variables 
held constant. Meanwhile, each additional increment in the z-score for regional accessibility relates to a $14 \%$ decline in health driving distance.

Discretionary and work driving distances negatively impact health-care distance traveled by car by $0.6 \%$ and $0.7 \%$, respectively, while keeping other variables constant at their means.

\section{Discretionary travel}

The number of cars within a household has a significantly significant positive impact on distance traveled by car for discretionary purposes, each additional car corresponds to a $4 \%$ increase in VKT for discretionary purpose. As the number of adults increases, distance driven declines by $5 \%$. Each year of age corresponds to a $2 \%$ increase in discretionary distance traveled, up to a point, all else equal.

Women drives $9 \%$ less discretionary driving distance compared to men. Hailing from a lower-income household is associated with $14 \%$ less discretionary driving distance; coming from a medium-income household corresponds to $4 \%$ fewer VKT compared to those from higher income household, while keeping all other variables constant at their mean.

Here, only local, rather than regional, accessibility has a statistically significant correlation. Each additional increment in the z-score for the home neighborhood Walk Score point corresponds to $14 \%$ less discretionary VKT. This result is perhaps unsurprising, but it does underscore the notion central to this research that travel decisions made for different purposes are subject to different considerations. It is conceivable - even likely - that people are be obliged to travel further from home for less discretionary purposes, such as work. But for discretionary purposes, they may opt for destinations closer at hand, meaning that the ability to travel regionally by transit is of less importance in this context.

School, healthcare, and work distance driven are all significant, highlighting the notion that discretionary travel is, in fact, discretionary and therefore subject to the constraints imposed by other travel demands. Each additional kilometer driven for each of those categories is associated with a $1 \%$ decline in discretionary driving distance, all else equal.

\section{DISCUSSION}

These results suggest a range of policy options for reducing individual VKT. The varying patterns of significance across travel purposes also suggests that policy responses must be conceived and targeted in different ways. Given the statistical significance of many of the socioeconomic variables, it is also clear that not all these policies will relate directly to the built environment, although changes to the built environment and transport systems may serve as essential prerequisites or supports.

First and foremost, our findings suggest that addressing car ownership must be a much greater portion of the policy puzzle when it comes to reducing transport-related VKT. Among all the variables studied, the presence of additional cars in the household represents the only consistently statistically significant relationship across all categories of travel for both the binary decision to drive and the distance driven once that decision is made. Policies in this regard might include incentives for eschewing a car altogether, such as free or discounted transit passes. These polices might also include using pricing mechanisms, such as sales and property taxes, congestion charging and registration and parking fees, to dissuade travelers from having or using a car when possible (36). In many places, however, car ownership remains essential for basic day-to-day activities such as work and shopping. To avoid unduly burdening car-dependent residents, policymakers may wish to consider progressive approaches to pricing that make each additional 
car incrementally more expensive. Currently, among all households retained our analysis the ratio of cars to adults in each household is approximately 0.8 ; among drivers the ratio is higher at 0.88 .

Second, local and regional accessibility show consistent impacts on driving and driving distance across most travel purposes considered. In the aggregate - and in combination with other initiatives - accessibility-focused planning efforts may therefore prove influential both directly and as support for other initiatives (17). For example, enhancing accessibility by transit and other modes may reduce the perceived need to purchase additional cars.

Third, patterns in the role played by demographic and socio-economic characteristics render equity a vital consideration. The data show, for example, that people from lower-income households are far more likely to drive than people from wealthier households. But in many cases, these same people are likely to drive shorter total distances for both work and discretionary purposes than people from higher-income households. This finding suggests different spatial patterns of employment in the Montreal region as lower-income jobs may be more broadly dispersed. Policymakers could potentially take advantage of the differential in driving distances by income group to soften the financial impact of future road pricing mechanisms(37). They could for example, apply charges over a certain annual or monthly threshold of driving. These particular results may also indicate that people from wealthier households are better served by transport alternatives, affording them greater opportunity to select their mode of transport to their preferred destinations, especially for work purpose, which is consistent with the findings of other studies exploring inequity in transport systems that find the wealthy generally travel faster and further than the lower income groups (38).

\section{CONCLUSIONS}

Understanding the conditions policymakers can adjust to reduce the impact of rising individual car travel represents a fundamental and enduring challenge. The stakes are high as communities across the world confront an unfolding climate crisis. Transport emissions represent a large and growing fraction of total emissions in both Canada and the United States. Reducing them will require a wide range of options and tools, one of which may be to further refine approaches for urban planning with an eye towards at least allowing people to comfortably, conveniently, and safely make the choice not to travel by car (39).

Much remains to be explored when considering the highly idiosyncratic and contextspecific nature of travel behavior and driving decisions. Yet the research to date and this study clearly indicate that many factors with a demonstrable influence fall squarely within planners' and city officials' control. As other researchers have noted, "residents do tend to drive less and use other modes more often when they live in compact areas, all else being equal" (39) p. 26. When combined, the of the 5Ds individually may yield large reductions in total vehicle distance traveled. Though important from the standpoint of cutting GHG emissions, reductions in mobile travel will certainly provide other additional benefits, including decreases in other air- and water-borne pollution, less costly travel, fewer roadway deaths and injuries, and more lively streetscapes.

In many respects, accessibility and the other Ds merely enable more responsible and sustainable transport choices. The rest remains up to people and their individual and collective choices. This strongly suggests the need to pursue these policies in conjunction with a broader range of supportive tools, such as road pricing. In the meantime, promising areas of additional research remain to eventually put Montreal drivers and others on the "short" road instead of the long one. 


\section{ACKNOWLEDGMENTS}

The authors wish to thank Rania Wasfi and Boer Cui for their assistance with the statistical modeling and Maddie Harreman-Fernandes for serving as a sounding board and providing valuable insight into the accessibility literature. James also wishes to thank his husband, David, for tolerating and even encouraging his endless studies. Finally, thanks to Robin Deboosere for developing the $\mathrm{R}$ script that eliminated the tedium of calculating jobs accessibility by census tract.

\section{AUTHOR CONTRIBUTIONS}

The authors confirm contribution to the paper as follows: study conception and design: DeWeese \& El-Geneidy; data collection: DeWeese \& El-Geneidy; analysis and interpretation of results: DeWeese \& El-Geneidy; draft manuscript preparation DeWeese \& El-Geneidy. All authors reviewed the results and approved the final version of the manuscript. 


\section{REFERENCES}

[1] Bush, E., and D. S. Lemmen. Canada's Changing Climate Report.In, Government of Canada, 2019. p. 444.

[2] U.S. Environmental Protection Agency. Inventory of U.S. Greenhouse Gas Emissions and Sinks, Washington, D.C. https://www.epa.gov/ghgemissions/inventory-us-greenhouse-gasemissions-and-sinks.

[3] Environment and Climate Change Canada. Greenhouse gas emissions.

[4] Xia, T., Y. Zhang, S. Crabb, and P. Shah. Cobenefits of Replacing Car Trips with Alternative Transportation: A Review of Evidence and Methodological Issues. Journal of Environmental and Public Health, Vol. 2013, 2013.

[5] Cervero, R., and J. Murakami. Effects of Built Environments on Vehicle Miles Traveled: Evidence from 370 US Urbanized Areas. Vol. 42, No. 2, 2010, pp. 400-418.

[6] Cervero, R., and R. Gorham. Commuting in transit versus automobile neighborhoods. Journal of the American Planning Association, 2009.

[7] Giuliano, G., and K. Small. Is the journey to work explained by urban structure? Urban Stud, Vol. 30, 1993, pp. 1485-1500.

[8] Zhang, L., J. Hong, A. Nasri, and Q. Shen. How built environment affects travel behavior: A comparative analysis of the connections between land use and vehicle miles traveled in US cities. Journal of Transport and Land Use, Vol. 5, No. 3, 2012.

[9] Ewing, R. B., Keith \& Winkelman, Steve \& Walters, Jerry \& Chen, Don. Growing Cooler: The Evidence on Urban Development and Climate Change. Urban Land Institute.

[10] Geurs, K., and B. van Wee. Accessibility evaluation of land-use and transport strategies: Review and research directions. Journal of Transport Geography, Vol. 12, 2004, pp. 127-140.

[11] Cui, B., G. Boisjoly, A. El-Geneidy, and D. Levinson. Accessibility and the journey to work through the lens of equity. Journal of Transport Geography, Vol. 74, 2019, pp. 269-277.

[12] Hansen, W. How accessibility shapes land use. Journal of the American Institute of Planners, Vol. 25, No. 2, 1959, pp. 73-76.

[13] Grengs, J., J. Levine, S. Qing, and S. Qingyun. Intermetropolitan Comparison of Transportation Accessibility: Sorting Out Mobility and Proximity in San Francisco and Washington, D.C. Vol. 29, No. 4, 2010, pp. 427-443.

[14] Geurs, K. T., and B. van Wee. Accessibility evaluation of land-use and transport strategies: review and research directions. Journal of Transport Geography, Vol. 12, No. 2, 2004, pp. 127140.

[15] Iacono, M., K. Krizek, and A. M. El-Geneidy. Access to destinations: How close is close enough? Estimating accurate distance decay functions for multiple modes and different purposes. 2008.

[16] Choi, K. The influence of the built environment on household vehicle travel by the urban typology in Calgary, Canada. Cities, Vol. 75, 2018, pp. 101-110.

[17] Ewing, R., and R. Cervero. "Does Compact Development Make People Drive Less?" The Answer Is Yes. Journal of the American Planning Association, Vol. 83, No. 1, 2017, pp. 19-25.

[18] Nelson, A. C. Compact Development Reduces VMT: Evidence and Application for Planners-Comment on “Does Compact Development Make People Drive Less?". Journal of the American Planning Association, Vol. 83, No. 1, 2017, pp. 36-41.

[19] Singh, A., S. Astroza, V. Garikapati, R. Pendyala, C. Bhat, and P. Mokhtarian. Quantifying the relative contribution of factors to household vehicle miles of travel. Transportation Research Part D: Transport and Environment, Vol. 63, 2018, pp. 23-36. 
[20] Wachs, M., and T. G. Kumagai. Physical accessibility as a social indicator. Socio-Economic Planning Sciences, Vol. 7, No. 5, 1973, pp. 437-456.

[21] Boisjoly, G., and A. M. El-Geneidy. How to get there? A critical assessment of accessibility objectives and indicators in metropolitan transportation plan. Transport Policy, Vol. 55, 2017, pp. $38-50$.

[22] Handy, S., and D. A. Niemeier. Measuring accessibility: an exploration of issues and alternatives. Environment and Planning A, Vol. 29, 1997, pp. 1175-1194.

[23] Kockelman, K. Travel Behavior as Function of Accessibility, Land Use Mixing, and Land Use Balance: Evidence from San Francisco Bay Area. Vol. 1607, 1997, pp. 116-125.

[24] Ewing, R., G. Tian, J. Goates, M. Zhang, M. J. Greenwald, A. Joyce, J. Kircher, and W. Greene. Varying influences of the built environment on household travel in 15 diverse regions of the United States. Urban Studies, Vol. 52, No. 13, 2015, pp. 2330-2348.

[25] Cervero, R., and M. Duncan. 'Which Reduces Vehicle Travel More: Jobs-Housing Balance or Retail-Housing Mixing? Journal of the American Planning Association, Vol. 72, No. 4, 2006, pp. 475-490.

[26] Handy, S., X. Cao, and P. Mokhtarian. Correlation or causality between the built environment and travel behavior? Evidence from Northern California. Transportation Research Part D: Transport and Environment, Vol. 10, No. 6, 2005, pp. 427-444.

[27] Agence métropolitaine de transport. Enquête origine-destination, 2013.In, Montréal., 2013.

[28] Gabriel Sicotte, C. M., Bilal Farooq. Comparison Between Trip and Trip Chain Models: Evidence from Montreal Commuter Train Corridor. CIRRELT, Vol. CIRRELT-2017, No. 35, 2017.

[29] Boeing, G. OSMnx: Python for Street Networks.In gboeing, 2016.

[30] Score, W. https://www.walkscore.com/about.shtml. Accessed 12 July 2019.

[31] Statistics Canada. Employed Labour Force 15 Years and Over Having a Usual Place of Work by Income Groups in 2015 (27) and Mode of Transportation (20), for Commuting Flow for Canada, Alberta, its Census Metropolitan Areas, its Tracted Census Agglomerations, its Census Tracts, Elsewhere in Alberta and Elsewhere in Canada, 2016 Census - 25\% Sample Data.In 2016 Census of Population, No. CO-1757 Table 5, 2016.

[32] ---. Main Mode of Commuting (20), Commuting Duration (7), Time Leaving for Work (7), Sex (3) and Age (11B) for the Employed Labour Force Aged 15 Years and Over Having a Usual Place of Work or No Fixed Workplace Address, in Private Households of Canada, Provinces and Territories, Census Metropolitan Areas and Census Agglomerations, 2016 Census - 25\% Sample Data.In, 2016.

[33] W. Holmes Finch, J. E. B., Ken Kelley. Multilevel Modeling in R. CRC Press, Boca Raton, Florida, 2014.

[34] Cui, B., E. Grisé, A. Stewart, and A. El-Geneidy. Measuring the Added Effectiveness of Using Detailed Spatial and Temporal Data in Generating Accessibility Measures. Transport Findings, 2019.

[35] Boisjoly, G., and A. El-Geneidy. Daily fluctuations in transit and job availability: A comparative assessment of time-sensitive accessibility measures. Journal of Transport Geography, Vol. 52, 2016, pp. 73-81.

[36] Camacho, A. E. a. K., Melissa and Marantz, Nicholas and Weil, Gabriel. Mitigating Climate Change Through Transportation and Land Use Policy Environmental Law Reporter, Vol. 49, No. $5,2019$. 
[37] Robitaille, A. M., J. Methipara, and L. Zhang. Effectiveness and Equity of Vehicle Mileage Fee at Federal and State Levels. Transportation Research Record: Journal of the Transportation Research Board, Vol. 2221, No. 1, 2011, pp. 27-38.

[38] Banister, D. Inequality in Transport. Alexandrine Press, Oxford, UK. , 2018.

[39] Handy, S. Thoughts on the Meaning of Mark Stevens's Meta-Analysis. Journal of the American Planning Association, Vol. 83, No. 1, 2017, pp. 26-28. 